\title{
ОТТОК НАСЕЛЕНИЯ ИЗ РЕГИОНОВ ДАЛЬНЕГО ВОСТОКА РОССИИ: ТЕНДЕНЦИИ И ПРИЧИНЫ *
}

\author{
(c) 2019 Олейник Елена Борисовна \\ доктор экономических наук, профессор кафедры Бизнес-информатики и экономико- \\ математических методов, Школа экономики и менеджмента \\ Дальневосточный федеральный университет, Россия, Владивосток \\ E-mail: oleinik.eb@dvfu.ru \\ (c) 2019 Шмидт Юрий Давыдович \\ доктор экономических наук, заведующий кафедрой Бизнес-информатики и экономико- \\ математических методов, Школа экономики и менеджмента \\ Дальневосточный федеральный университет, Россия, Владивосток \\ E-mail: syd@dvfu.ru
}

\section{(C) 2019 Карп Дмитрий Борисович}

кандидат экономических наук, доцент кафедры Бизнес-информатики и экономикоматематических методов, Школа экономики и менеджмента Дальневосточный федеральный университет, Россия, Владивосток

E-mail: karp.db@dvfu.ru

Проведен сравнительный анализ миграционного оттока из субъектов Дальневосточного федерального округа. Проведен сравнительный анализ моделей временных рядов и выбрана авторегерессионная модель для краткосрочного прогнозирования тенденции оттока населения. Построена модель на панельных данных, с помощью которой получены экономические факторы, значимо влияющие на уменьшение миграционного оттока. Выделены социальные факторы, влияющие на увеличение оттока населения из субъектов региона. Сделан вывод, что миграционный отток - системная проблема, имеющая не только экономические, но и социальные причины.

Ключевые слова: миграционный отток, Дальневосточный регион, модель с фиксированными эффектами, среднедушевой доход, экономические и социальные факторы

Развитие Дальневосточного региона имеет большое значение для экономической безопасности и территориальной целостности России.

С 2013 г., когда была принята и начала выполняться федеральная целевая программа «Экономическое и социальное развитие Дальнего Востока и Байкальского региона на период до 2025 года» [1], прирост промышленного производства в ДФО составил $23 \%$, тогда как по России $-8,3 \%$ [4]. Реализация этой программы направлена в частности на решение одной из самых больших проблем развития региона - уменьшение численности населения. Притоку населения также должны способствовать развитие территорий опережающего развития и особых экономических зон, а также программа «Дальневосточный гектар». С 2015 г. для инвесторов на Дальнем Востоке появились территории опережающего развития (ТОР) и свободный порт Владивосток (СПВ). Резиденты таких зон получают льготы взамен на инвестиции. С момента появления ТОРов в регион пришло почти 284 млрд. руб. частных инвестиций, по данным Минвостокразвития. В 2017 г. по данным Росстата, объем инвестиций в основной капитал в Дальневосточном федеральном округе (ДВФО) составил 1,217 трлн. рублей или 117,1\% по отношению к 2016 году.

На первый взгляд в дальневосточном регионе все экономические показатели достаточно стабильны. В первом полугодии 2018 года средняя номинальная заработная плата в ДВФО составляет 52,8 тыс. руб. в месяц, что выше среднего по России показателя на $24 \%$. Средний по регионам Дальнего Востока размер прожиточного минимума в полтора раза выше среднего по России: 15,3 тыс. руб. против 10,0 тыс. руб.

\footnotetext{
" Работа выполнена в рамках гранта РФФИ № 19-010-00206 «Моделирование миграционных потоков территорий и оценка результативности инструментов миграционной политики»
} 
Таблица 1. Общие итоги миграции населения в 2018 году

\begin{tabular}{|l|c|c|c|c|c|}
\hline \multicolumn{1}{|c|}{ Территория } & $\begin{array}{c}\text { Число прибыв- } \\
\text { ших, человек }\end{array}$ & В \% к 2017 г. & $\begin{array}{c}\text { Число выбыв- } \\
\text { ших, человек }\end{array}$ & В \% к 2017 г. & $\begin{array}{c}\text { Миграцион- } \\
\text { ный прирост } \\
(+), \text { уыль } \\
\text { человек }\end{array}$ \\
\hline Российская Федерация & $\mathbf{4 9 1 0 9 0 7}$ & $\mathbf{1 0 2 , 9}$ & $\mathbf{4 7 8 6 0 2 3}$ & $\mathbf{1 0 4 , 9}$ & $+\mathbf{1 2 4 8 8 4}$ \\
\hline $\begin{array}{l}\text { Дальневосточный } \\
\text { федеральный округ }\end{array}$ & $\mathbf{3 2 8 4 6 6}$ & $\mathbf{1 0 1 , 0}$ & $\mathbf{3 6 1 6 0 9}$ & $\mathbf{1 0 2 , 3}$ & $\mathbf{- 3 3 1 4 3}$ \\
\hline Республика Бурятия & 41176 & 101,5 & 45751 & 104,0 & -4575 \\
\hline Республика Саха (Якутия) & 42338 & 104,0 & 45278 & 99,8 & -2940 \\
\hline Забайкальский край & 29262 & 104,9 & 36683 & 102,3 & -7421 \\
\hline Камчатский край & 14837 & 108,7 & 15539 & 118,6 & -702 \\
\hline Приморский край & 77913 & 103,0 & 82567 & 101,7 & -4654 \\
\hline Хабаровский край & 53212 & 95,9 & 58143 & 98,3 & -4931 \\
\hline Амурская область & 29396 & 99,4 & 32788 & 103,5 & -3392 \\
\hline Магаданская область & 7083 & 88,7 & 9746 & 103,9 & -2663 \\
\hline Сахалинская область & 24327 & 97,2 & 24651 & 108,8 & -324 \\
\hline Еврейская авт.область & 3521 & 82,9 & 5299 & 85,6 & -1778 \\
\hline Чукотский авт.округ & 5401 & 123,6 & 5164 & 102,7 & +237 \\
\hline
\end{tabular}

Источник: [6]

Средняя добавленная стоимость на одного занятого в экономике Дальневосточного региона составила 1172 тыс. руб., что на 22\% выше общероссийского уровня (по данным за 2016 год) [3].

Уровень безработицы в ДВФО в первом полугодии 2018 г. снизился до 5,7\%, а численность безработных составляет 272 тыс. чел.- минимальна в сравнении с другими регионами [6,7]. Однако, несмотря на все принятые меры, Дальний Восток является регионом, в котором наблюдается максимальный среди всех российских регионов отток населения (табл.1).

Методология исследования. Для краткосрочного прогнозирования и оценки оттока населения из ДВФО в целом предлагается построить использовать две модели временного ряда: адаптивную модель Хольта-Уинтерса и модель ARIMA, а затем выбрать лучшую по минимальной среднеквадратической ошибке. В моделях $X_{t}-$ исходный временной ряд, каждый элемент которого - ежегодный отток населения.

1. Адаптивная модель Хольта-Уинтерса является модификацией метода экспоненциального сглаживания. В качестве модели ряда используется его представление в виде мультипликативной комбинации линейного тренда с сезонной составляющей. [2, 9]. Модель содержит основное уравнение прогноза и два сглаживающих уравнения, которые отвечают за уровень ряда и тренд и представлены формулами (1-4):

$$
\begin{aligned}
& F_{t+h}=\left(l_{t}+h b_{t}\right) S_{t+h-n} \\
& l_{t}=\alpha \frac{y_{t}}{S_{t-n}}+(1-\alpha)\left(l_{t-1}+b_{t-1}\right), \\
& b_{t}=\beta\left(l_{t}-l_{t-1}\right)+(1-\beta) b_{t-1} \\
& S_{t}=\gamma \frac{y_{t}}{l_{t-1}+b_{t-1}}+(1-\gamma) S_{t-n}
\end{aligned}
$$

Уравнение (1) является основным в данной модели. Оно отражает сам прогноз значения временного ряда на период $t+h$, который можно выполнить на основе данных, имеющихся в момент времени $t ; l_{t}$ описывает уровень ряда с учетом сезонности $S_{t-n}$, а $b_{t}$ - поведение тренда. Параметр $\alpha$-коэффициент сглаживания сезонности, $\beta$-коэффициент сглаживания тренда. Уравнение (4) в модели, отражающее сезонность, является средневзвешенным между текущим индексом сезонности (в момент времени $t$ ) и индексом сезонности того же периода в прошлом году. Отсюда возникает значение $t-n$ и новый параметр - $\gamma$. Он отвечает за сглаживание сезонности. Параметры $\alpha, \beta$ и $\gamma$ принимают значения в интервале от 0 до 1 .

2. Авторегрессионная модели ARIMA [10] может быть представлена уравнением (5):

$$
\Delta^{d} X_{t}=c+\sum_{i=1}^{p} a_{i} \Delta^{d} X_{t-i}+\sum_{j=1}^{q} b_{j} \varepsilon_{t-j}+\varepsilon_{t},(5)
$$


где $\varepsilon_{\mathrm{t}}-$ стационарный временной ряд, $c, a_{i}$, $b_{j}$ - параметры модели, $\Delta$ d - оператор конечной разности временного ряда порядка $\mathrm{d}$.

Модели реализованы в среде R-Studio

3. Для прогнозирования оттока населения по субъектам ДВФО и учета факторов, влияющих на миграцию предлагается использовать модель панельных данных с фиксированными эффектами, которая опирается на структуру панельных данных, что позволяет учитывать неизмеримые индивидуальные различия объектов. Эти отличия называются эффектами. В модели с фиксированным эффектом считается, что каждая экономическая единица «уникальна» и не может рассматриваться как результат случайного выбора из некоторой генеральной совокупности. Такой подход вполне оправдан, когда речь идет о странах или крупных регионах.

Введем обозначения:

$i=1, \ldots, n-$ номера объектов, $t=1, \ldots, T-$ моменты времени, $k-$ число признаков; $x_{i t}-$ набор независимых переменных (вектор размерности $k) ; y_{i t}-$ зависимая переменная для экономической единицы $i$ в момент времени $t$; $\varepsilon_{i t}-$ соответствующая ошибка. Обозначим также:

$$
\begin{gathered}
y_{i}=\left[\begin{array}{l}
y_{i 1} \\
\dddot{y}_{i T}
\end{array}\right], X_{i}=\left[\begin{array}{c}
x_{i 1}^{\prime} \\
\cdots \\
x_{i T}^{\prime}
\end{array}\right], \varepsilon_{i}=\left[\begin{array}{l}
\varepsilon_{i 1} \\
\dddot{\varepsilon}_{i T}
\end{array}\right] . \\
y=\left[\begin{array}{c}
y_{1} \\
\dddot{y}_{n}
\end{array}\right], X=\left[\begin{array}{c}
X_{1} \\
\dddot{X}_{n}
\end{array}\right], \varepsilon=\left[\begin{array}{l}
\varepsilon_{1} \\
\ddot{\varepsilon}_{n}
\end{array}\right] .
\end{gathered}
$$

Где у и X панельные («объединенные») наблюдения и ошибки, у и $\varepsilon-$ векторы размерностью $n T \mathrm{x} 1, \mathrm{X}$ - матрица регрессоров размерностью $n T x k$. Во введенных обозначениях модель панельных данных с фиксированными эффектами описывается уравнением (6)

$$
\begin{aligned}
& y_{i t}=\alpha_{i}+x_{i t}^{\prime} \cdot \beta+\varepsilon_{i t} \\
& \beta \in \mathbb{R}^{k}, \alpha_{i} \in \mathbb{R}(i=1, \ldots, n)
\end{aligned}
$$

Величина $\alpha_{i}$ выражает индивидуальный эффект объекта $i$, не зависящий от времени $t$, при этом регрессоры $x_{i t}$ не содержат константу. Модель реализована с помощью эконометрического пакета Gretl.

Результаты исследования. Источником данных для анализа и прогнозирования явля- лись материалы сайтов Федеральной службы государственной статистики [8]. Для моделирования тенденции временного ряда «Отток населения из ДВФО» с 1997 по 2018 гг. были предложены две модели различных типов, адекватные исходным данным:

1) ARIMA $(1,0,1)$. Среднеквадратическая ошибка $S e=5410,0$. Уравнение:

$$
y_{t}=264949,52-0,883 y_{t-1}+0,749 \varepsilon_{t-1}+\varepsilon_{t}
$$

2) Модель Хольта-Уинтерса. Среднеквадратическая ошибка $\mathrm{Se}=6100,18$. Модель описывается следующей системой:

$$
\left\{\begin{array}{c}
F_{t+h}=l_{t}+h b_{t}+S_{t+h-n} \\
l_{t}=0,998\left(y_{t}-S_{t-n}\right)+0,002\left(l_{t-1}+b_{t-1}\right) \\
b_{t}=0,8922\left(l_{t}-l_{t-1}\right)+0,1078 b_{t-1} \\
S_{t}=0
\end{array}\right.
$$

Остатки этих моделей в соответствии с тестом Льюнга-Бокса являются случайными. Сравнительный анализ ошибок позволил выбрать модель ARIMA $(1,0,1)$. Прогноз оттока населения из ДВФО на 2019 год и границы доверительных интервалов:

$\begin{array}{ll}\text { Point } & 2019 \\ \text { Forecast } & \mathbf{4 0 6 5 9 0} \\ \text { Lo 80 } & 371597.1 \\ \text { Hi 80 } & 441583.0 \\ \text { Lo 95 } & 353072.9 \\ \text { Hi 95 } & 460107.2\end{array}$

Результаты моделирования позволили сделать вывод, что в 2019 г. отток населения возрастет на 406590 человек (или на 12,4\%).

3) Для анализа факторов, имеющих значимое влияние на миграционный отток, в качестве регрессоров были выбраны следующие показатели по каждому субъекту ДВФО: Объем валового регионального продукта (ВРП) на душу населения, руб, Численность населения в регионе, тыс. чел., Среднедушевой доход в регионе, руб., Оборот розничной торговли на душу населения в регионе, руб., Объем инвестиций в регионе (в основной капитал), млн. руб. на 1000 чел.

4) Проверка на аномальность значений выявила в качестве аутлаера (outlier) Сахалинскую область: там наблюдается значительно больший, чем в других субъектах ДВФО объем ВРП на душу населения (рис.1).

Такие «выбросы» объясняются добычей и экспортом нефти и газа, освоение которых осу- 


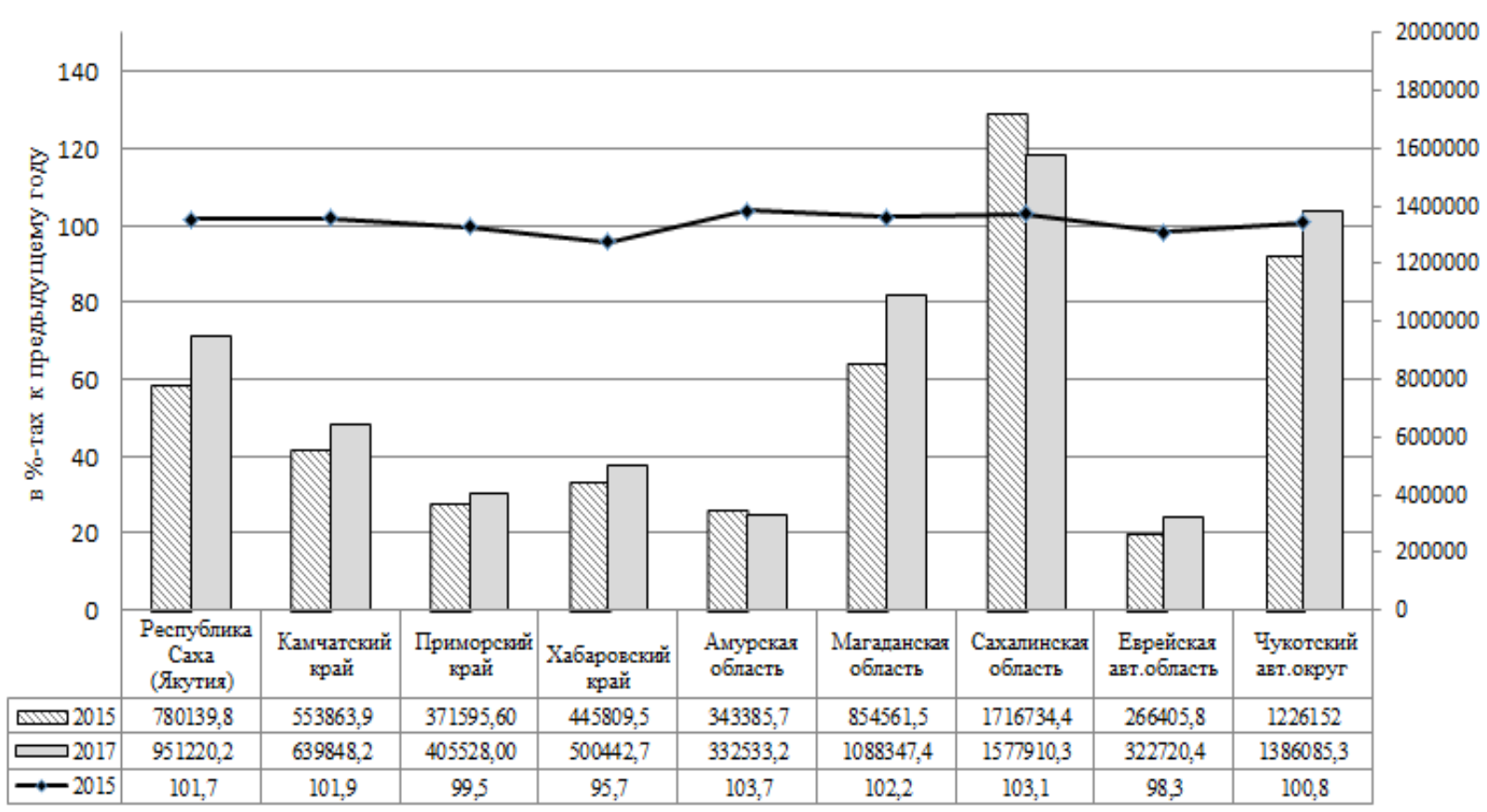

Рис. 1. ВРП на душу населения в 2015 и 2017 гг. и индекс физического объема ВРП в субъектах ДВФО в 2015 г. Источник: рассчитано по данным [8]

ществляется за счет иностранных инвестиций. Поэтому ситуацию с миграционным оттоком населения в Сахалинской области надо рассматривать отдельно. По остальным данным составлена панель исходных данных по субъектам региона за период 1997-2017 гг. В этот период в состав ДВФО еще не были включены Забайкальский край и республика Бурятия.

5) В число регрессоров была добавлена категориальная переменная, Climat, которая характеризует климатические условия субъектов ДВФО, и принимают следующие значения: 1 для Чукотского АO; 2 - для Магаданской области и республики Саха (Якутия); 3 - для Хабаровского края, 4 - для Сахалинской и Амурской области, Камчатского края и Еврейской АО, 5 - для Приморского края.

Также была сконструирована искусственная переменная Vrp_Climat=Vrp_Persan*Climat, которая характеризует ВРП на душу населения с учетом «поправки» на суровость климатических условий территории. В результате была построена модель с фиксированными эффектами (рис.2), имеющая значимые коэффициенты и хорошо интерпретируемые знаки при них.

В соответствии с результатами теста на различие констант в группах (p-значение < 0,05), предпочтительнее панельная регрессия с фиксированными эффектами, а не обычная pooled- регрессия. Зависимая переменная l_out - это логарифм оттока населения по каждому региону; d_Dohod_pers и d_Vrp_Climat - абсолютные приросты переменных «Среднедушевой доход в регионе» и «ВРП на душу населения с учетом климатических условий». Все остальные факторы были исключены из панельной регрессии либо как незначимые, либо как имеющие неинтерпретируемый знак. Знак «минус» при коэффициентах указывает на обратную зависимость между переменными, то есть при увеличении регрессора, результирующий показатель оттока населения снижается. Наиболее значимым является прирост дохода на душу населения в каждом из рассматриваемых регионов, а также ВРП на душу населения с учетом климатических условий. Коэффициенты меньше 1, поэтому хорошо интерпретируются: так как зависимая переменная в логарифмах, то коэффициенты регрессии показывают, что увеличение прироста дохода на 1 руб. уменьшит отток населения на $(e$ d_Dohod_pers -1) =5,82676е-05 процентов, а увеличение прироста ВРП на душу населения с учетом климатических условий на 1 руб. уменьшит отток населения на $\left(e d_{-}\right.$Vrp_Climat -1$)=0,150199$ процентов. Значение константы указывает на то, что воздействие ненаблюдаемых факторов будет удерживать миграционный отток на уровне 9,79\% в год. Панельная регрессия выявила эко- 
욕 gretl: модель 1

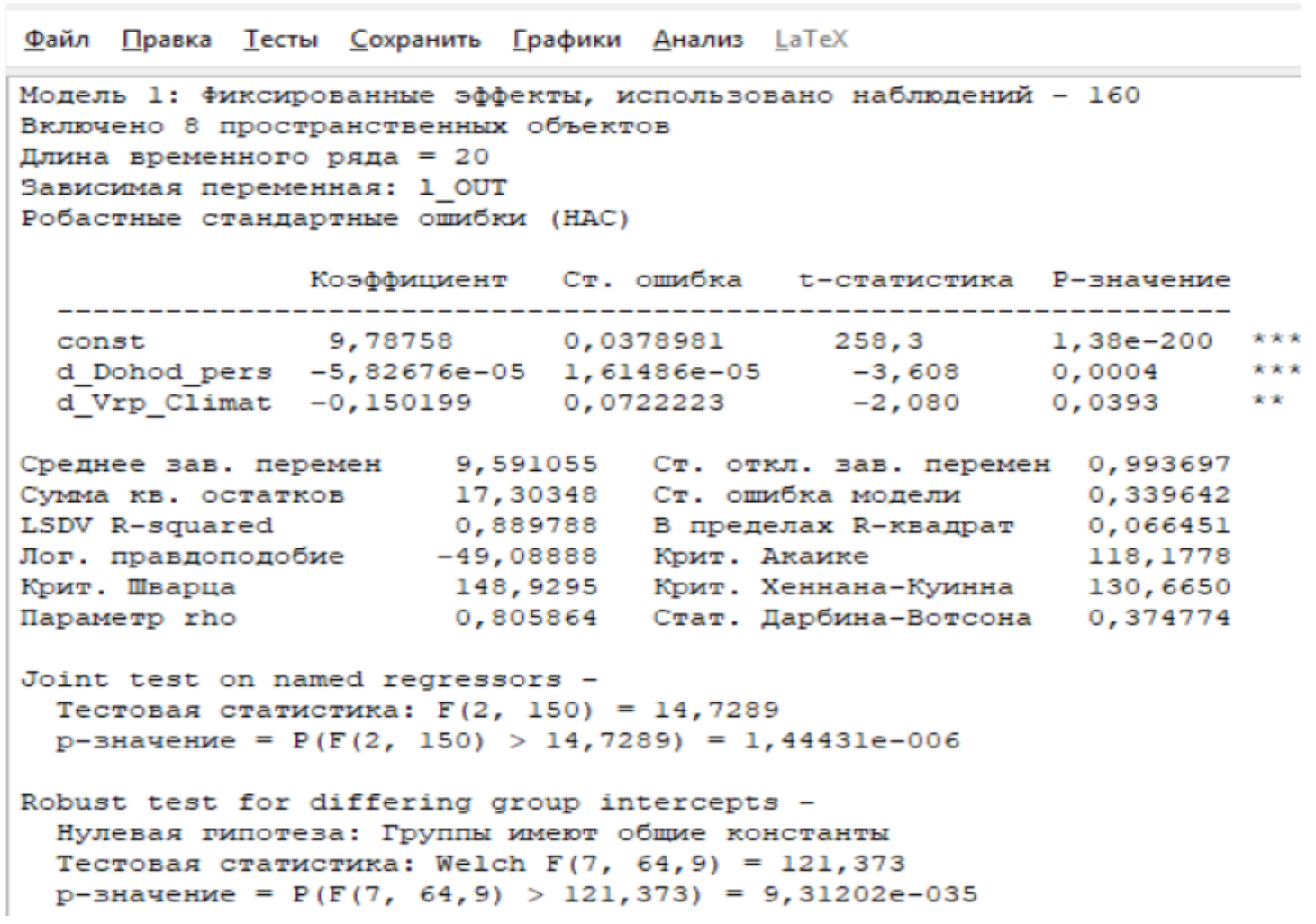

Puc. 2. Результаты построения панельной модели с фиксированными эффектами.

номические факторы, сдерживающие миграционный отток. Коэффициенты регрессии сравнительно малы.

Выводы. Так что же еще влияет на отток населения из ДВФО? Миграционный отток - системная проблема, имеющая не только экономические, но и социальные причины. Высокий уровень зарплат пропорционален ценам на товары, коммунальные услуги, что делает невозможными накопления получение квалифицированной медицинской помощи, обучение детей, на отдых. Люди испытывают дискомфорт из-за сурового климата, но при этом не получают компенсации. Все это на фоне растущей мобильности населения способствует росту миграционного оттока. По данным Росстата в 2017 г. самый высокий индекс стоимости жизни в Петропавловске-Камчатском и Анадыре 1,58. Сравнение с другими регионами позволит сформировать представление о ценах на Дальнем Востоке, индекс в Москве составляет 1,27; в Краснодаре - 0,99. Реальные располагаемые денежные доходы населения по сравнению с 2015 г. снизились до 94,2\% (РФ - 94,7\%), сократилась реальная заработная плата до 99,7\% (РФ -
$100,7 \%)$ и увеличилось число жителей с доходом меньшим, чем прожиточный минимум (табл. 2). При такой стоимости квадратного метра жилья рациональное поведение для жителей региона выгодно продать достаточно дорогую недвижимость на Дальнем Востоке и купить более подходящий вариант, который в некоторых случаях будет даже дешевле, в других регионах страны.

Приоритетами при переезде у них пользуются такие регионы, как Санкт-Петербург с Ленинградской областью, Калининградская область, Краснодарский край, отчасти Белгородская область [5]. В пяти субъектах ДВФО более $11 \%$ потребительских расходов приходится на оплату ЖКХ (в России 9,6\%). В Камчатской области этот показатель составил 15\% и является самым высоким в России. Уровень безработицы в 4-5\% означает, что дефицита рабочих мест нет, работают все, кто согласен работать, хотя бы за небольшие деньги. Дальнейший отток населения вызовет серьезный дефицит рабочей силы.

Проблема не только в том, что из Дальневосточного региона уезжают,- проблема также и в том, что сюда, в геостратегический регион не хотят приезжать. 
Таблица 2. Показатели социально-экономической ситуации в Дальневосточном федеральном округе, 2018 г.

\begin{tabular}{|c|c|c|c|c|}
\hline Территория & $\begin{array}{c}\text { Жителей с дохо- } \\
\text { дом меньшим, } \\
\text { чем прожиточный } \\
\text { минимум,\% }\end{array}$ & $\begin{array}{c}\text { Доля потреби- } \\
\text { тельских расходов } \\
\text { средне статистич. } \\
\text { семьи, потрачен- } \\
\text { ных на оплату } \\
\text { ЖКХ,\%, (в скобках- } \\
\text { рейтинг регионов } \\
\text { России) }\end{array}$ & $\begin{array}{c}\text { Долги субъекта } \\
\text { в федеральный } \\
\text { бюджет, млрд. руб. }\end{array}$ & $\begin{array}{c}\text { Средняя цена } 1 \\
\text { кв.м. жилой пло- } \\
\text { щади на вторич- } \\
\text { ном рынке жилья, } \\
\text { руб. }\end{array}$ \\
\hline Российская Федерация & 12,9 & $9,6(-)$ & - & 53574 \\
\hline ДВФО & 14,6 & Нет данных & 171,66 & 67027 \\
\hline Республика Саха (Якутия) & 19 & $8,4(18)$ & 50,36 & 72380 \\
\hline Камчатский край & 16,5 & $15(85)$ & 4,04 & 60445 \\
\hline Приморский край & 13,9 & $10,1(46)$ & 5,21 & 89994 \\
\hline Хабаровский край & 12 & $11,7(72)$ & 54,94 & 60030 \\
\hline Амурская область & 15,1 & $11,8(73)$ & 27,4 & 52938 \\
\hline Магаданская область & 11,3 & $14(74)$ & 13,2 & 47230 \\
\hline Сахалинская область & 9,6 & $8,4(18)$ & 0,00 & 107267 \\
\hline Еврейская авт.область & 24,6 & $8,7(22)$ & 5,71 & 38343 \\
\hline Чукотский авт.округ & 9,5 & $12,6(78)$ & 10,8 & Нет данных \\
\hline Источник: & http://vostok.today/ & $\begin{array}{c}\text { https://ria. } \\
\text { ru/20190916/ } \\
\text { 1558655432.html }\end{array}$ & $\begin{array}{l}\text { http://fincan. } \\
\text { ru/articles/93 } \\
\text { dolgi-regionov- } \\
\text { rossii-2019 }\end{array}$ & $\begin{array}{l}\text { https://fedstat.ru/ } \\
\text { indicator/31452 }\end{array}$ \\
\hline
\end{tabular}

\section{Библиографический список}

1 Государственная программа «Социально-экономическое развитие Дальневосточного федерального округа» [Электронный ресурс].- Электрон. дан.- Режим доступа: http://government.ru/rugovclassifier/ section/2649/ (дата обращения 10.11.2019)

2 Дегтярева, Н.А. Модели анализа и прогнозирования на основе временных рядов: монография / Н.А. Дегтярева.- Челябинск: Изд-во ЗАО «Библиотека А. Миллера, 2018.-160 с.

3 Деловой и финансовый климат Дальневосточного региона /под ред. С. Лавского.- Исследовательский центр компании «Делойт».- Москва. - 2018.- 40с. [Электронный ресурс].- Электрон. дан.- Режим доступа: http://governmen www2.deloitte.com (дата обращения 12.11.2019)

4 Козлов А. «О законодательном обеспечении опережающего социально-экономического развития Дальнего Востока и Арктики». Доклад на парламентских слушаниях » [Электронный ресурс].- Электрон. дан.- Режим доступа: https://minvr.ru/press-center/news/23774/ (дата обращения 12.11.2019)

5 Корниенко Е. Почему на Дальнем Востоке сложно купить жилье, даже если очень хочется? [Электронный peсурс].- Электрон. дан.- Режим доступа: https://iz.ru/932136 (дата обращения 17.11.2019)

6 Основные итоги социально-экономического положения Дальневосточного федерального округа в 2018 году [Электронный ресурс].- Электрон. дан.- Режим доступа: http://assoc.khv.gov.ru/news/3486 (дата обращения 12.11.2019)

7 Основные результаты работы Министерства Российской Федерации по развитию Дальнего Востока за 2017 год [Электронный ресурс].- Электрон. дан.- Режим доступа: http:/government.ru/dep_news/32247 (дата обращения 15.11.2019)

8 Официальный сайт Федеральной службы государственной статистики [Электронный ресурс].- Электрон. дан.- Режим доступа: http://www.gks.ru (дата обращения 15.11.2019)

9 Пьяных, А.А. Анализ применения комбинированных моделей при краткосрочном прогнозировании временных рядов// Журнал Сибирского федерального университета. Серия: Техника и технологии. 2014. -Т. 7. № 3.- С. 359-363

10 Тихомиров, Н.П. Методы эконометрики и многомерного статистического анализа / Н.П. Тихомиров.- М.: Экономика, 2017.- 989 с. 